OPEN ACCESS

Edited by:

Filipe Manuel Clemente Polytechnic Institute of Viana do

Castelo, Portugal

Reviewed by:

Mustafa Sögüt,

Kırıkkale University, Turkey

Ricardo Franco Lima

Polytechnic Institute of Viana do

Castelo, Portugal

*Correspondence:

Jakub Kokstejn

kokstejn@ftvs.cuni.cz;

jakubkokstejn@seznam.cz

Specialty section:

This article was submitted to

Exercise Physiology,

a section of the journal

Frontiers in Physiology

Received: 01 March 2019

Accepted: 26 April 2019

Published: 28 May 2019

Citation:

Kokstejn J, Musalek M

Wolanski P, Murawska-Cialowicz E and Stastny P (2019) Fundamental

Motor Skills Mediate the Relationship

Between Physical Fitness and Soccer-Specific Motor Skills

in Young Soccer Players.

Front. Physiol. 10:596.

doi: 10.3389/fphys.2019.00596

\section{Fundamental Motor Skills Mediate the Relationship Between Physical Fitness and Soccer-Specific Motor Skills in Young Soccer Players}

\author{
Jakub Kokstejn ${ }^{*}$, Martin Musalek ${ }^{1}$, Pawel Wolanski², Eugenia Murawska-Cialowicz ${ }^{2}$ and \\ Petr Stastny ${ }^{1}$
}

${ }^{1}$ Faculty of Physical Education and Sport, Charles University, Prague, Czechia, ${ }^{2}$ Department of Physiology and Biochemistry, University School of Physical Education, Wrocław, Poland

Fundamental motor skills (FMS) are the basic elements of more complex sport-specific skills and should be mastered at the end of early childhood; however, the relationship between FMS and sport-specific skills has not yet been verified in prepubertal soccer players. Therefore, the aim of this study was to determine the role of FMS in the process of acquiring soccer-specific motor skills (measured using speed dribbling) with regard to physical fitness and biological maturation. Forty male soccer players (11.5 \pm 0.3 years of age) at the highest performance level participated in the study. The test of Gross Motor Development - second edition and Unifittest 6-60 were used to assess FMS and physical fitness, respectively. The role of FMS in a complex theoretical model with the relationships between physical fitness, biological maturation and speed dribbling was analyzed by multiple regression path analyses (MRPA). Moderate to strong correlations were found between FMS, physical fitness, and speed dribbling $(r=0.56-0.66)$. Biological maturation did not appear to be a significant predictor of physical fitness or speed dribbling. The MRPA model using FMS as mediator variable between physical fitness and speed dribbling showed a significant indirect effect (standard estimation $=-0.31, p=0.001 ; R^{2}=0.25$ ). However, the direct correlation between physical fitness and speed dribbling was non-significant. Our results showed that FMS significantly strengthened the influence of physical fitness on the performance of speed dribbling, a soccer-specific motor skill, and thus play an important role in the process of acquiring sport-specific motor skills in prepubertal soccer players. When considering the long-term training process, especially during childhood and before puberty, a wide range of FMS activities should be applied for better and possibly faster acquisition of soccer-specific motor skills.

Keywords: pre-pubescence, soccer, skills, talent development, performance, motor control

\section{INTRODUCTION}

One of the main goals of professional soccer clubs and their youth academies is to develop young, talented players into successful professional players (Huijgen et al., 2013). Many clubs and national associations (e.g., Germany, Belgium, Portugal, Netherlands) have created programs for talent identification and development (TID) to provide the best training environment and 
conditions for young players with noticeable potential; enrollment in these programs often starts during early adolescence (Deutscher Fuûball Bund, 2009; Huijgen et al., 2014; Leyhr et al., 2018). A player's success in a soccer match depends on complex multidimensional performance that is influenced by technical, tactical, physical, anthropometric, and mental factors (Reilly et al., 2000; Forsman et al., 2016). To ensure the highest possible efficiency in the TID process, performance tests of different soccer domains outside the context of the soccer match and notational analysis (observation and quantitative/qualitative analysis of the technical and tactical actions performed during a match) are often used in addition to coaches' expert and highly subjective assessment methods (Aquino et al., 2017).

During the last two decades, technical-tactical skills and physical fitness in particular have been frequently explored and identified as key determinants of young players' game performance, serving as discriminants between elite, subelite and non-elite youth soccer players (Meylan et al., 2010; Unnithan et al., 2012; Höner et al., 2017; Serrano et al., 2017; Leyhr et al., 2018). In particular, technical skills such as dribbling the ball, passing, shooting and ball mastery are considered critical game rudiments (Rampinini et al., 2009) and have been recognized as important motor factors within TID programs (Vaeyens et al., 2006; Deutscher Fuûball Bund, 2009). Previous research suggests that technical skills develop most rapidly during the prepubertal and pubertal (10-15 years) phases (Vaeyens et al., 2006; Valentedos-Santos et al., 2012; Leyhr et al., 2018). Specifically, the test of speed dribbling is the best discriminator of performance levels among soccer players (Vaeyens et al., 2006; Huijgen et al., 2009). Elite young players display significantly better performance in strength, speed, agility and aerobic/anaerobic endurance (Vaeyens et al., 2006; Murtagh et al., 2018; Rommers et al., 2018) than subelite young players. However, any connections between these findings and current game performance in youth players should be made with caution because differences in physical fitness and tactical skills are often caused by differences in the speed of biological maturation (Vaeyens et al., 2008; Costa et al., 2010; Meylan et al., 2010; Unnithan et al., 2012; Cumming et al., 2018). Early maturing soccer players generally show higher levels of explosive performance, sprinting, agility and aerobic endurance (Figueiredo et al., 2009; Valente-dosSantos et al., 2012; Rommers et al., 2018). The relationship between biological maturation and the performance of technical skills is contradictory to the results of some studies confirming the influence of biological maturation status on the performance of technical skills tests (Philippaerts et al., 2006; Rommers et al., 2018) and other studies finding a lack of influence of biological maturation on the performance of technical skills (Figueiredo et al., 2009; Vandendriessche et al., 2012).

Recently, several studies have emphasized the importance of motor coordination, i.e., non-specific motor coordination, in the process of TID in youth soccer (Vandendriessche et al., 2012; Deprez et al., 2014; Deprez D. et al., 2015; Deprez D.N. et al., 2015; Rommers et al., 2018). Furthermore, these studies showed that motor coordination is a significant long-term predictor of specific aerobic fitness and explosive leg power in young soccer players (Deprez et al., 2014; Deprez D. et al., 2015) and does not depend on biological maturation (Vandendriessche et al., 2012; Rommers et al., 2018). However, the direct relationship between motor coordination and specific technical skills (e.g., speed dribbling) was not explored in prepubescent soccer players. In another study, Deprez D.N. et al. (2015) measured motor coordination performance among club players (playing in the two highest youth soccer leagues) and dropout players (those who dropped to lower soccer leagues) over the 8-year period from age 8 years to age 16 years and found that the club players performed significantly better than the dropout players on all motor coordination tasks and on aerobic endurance and speed. The authors suggested that motor coordination performance is essential for discriminating between players in a high-level training program and dropout players from the age of 9 years until late puberty. Although the direct relationship between motor coordination and specific technical skills was not investigated in this study, one could hypothesize that the dropped players had overall worse specific technical skills and worse motor coordination than club players.

In many studies focused on motor development, the term "motor coordination" has been used to denote motor competence, motor proficiency or fundamental motor skills (FMS) to describe goal-directed human movement (Robinson et al., 2015). For the purpose of our study, we decided to use the term FMS to describe the level of general motor competence. In general, according to several key motor development theoretical models, FMS are frequently defined as the "elements" of more advanced complex movements required to participate in sports, games, or other context-specific physical activity (Clark and Metcalf, 2002; Gallahue et al., 2012). However, no clear research evidence indicates whether this theory is valid in prepubertal soccer players. Once FMS are mastered, the learning of sport-specific skills can occur more quickly and be more effective (Gallahue et al., 2012). FMS are traditionally divided into object control/ball/manipulative skills (e.g., throwing, catching, dribbling), locomotor skills (e.g., running, jumping, galloping), and balance/stability skills (e.g., non-locomotor skills such as body rolling, one-foot balance, stretching, twisting) (Gallahue et al., 2012). Although children have the developmental potential to master most FMS by the age of 6 years (Gallahue et al., 2012), recent research highlights that children and adolescent youth do not perform FMS to their expected developmental capabilities (O'Brien et al., 2016). O'Brien et al. (2016) further demonstrated that while levels of FMS vary by country, performance levels remain consistently low, with the majority of children and adolescents failing to surpass $50 \%$ mastery in most skills.

To our knowledge, little attention has been paid to the importance of FMS in the process of acquiring technical skills (e.g., dribbling, receiving, or passing a ball) in prepubescent soccer players. Moreover, current research describes the direct relationships between technical skills and other physical, motor control, or morphological factors but have not described how those factors interact with or mediate specific soccer skills. Although there is clear evidence concerning the relationships between FMS, physical fitness and biological maturation, there 
is a lack of information about the influence of FMS on the performance of soccer technical skills in prepubescent-aged players. We hypothesized that FMS strengthen the influence of physical fitness and biological maturation on technical skills (e.g., speed dribbling the ball). Therefore, the aim of this study was to investigate the role of FMS in the relationships between physical fitness, biological maturation and technical skills in prepubescent soccer players.

\section{MATERIALS AND METHODS}

\section{Methodological Approach}

Cross-sectional measurement was performed during the competitive part of the soccer season. The participants were familiarized with the experimental protocol 1 week prior to the experiment and did not perform any exhausting activity $72 \mathrm{~h}$ before the experiment. After the participants' body mass (BM) was estimated, they performed the battery of FMS, speed dribbling and physical fitness tests within 1 day (two training sessions). The FMS and sit-ups (part of Unifittest 6-60) tests were performed indoors on a teraflex surface during the morning training session between 9 and $11 \mathrm{am}$. The rest of physical fitness tests were then conducted during afternoon training session on the outdoor ground with artificial grass between 3 and $5 \mathrm{pm}$.

\section{Participants}

The research sample consisted of forty U12 soccer players (mean $\pm \mathrm{SD}$; age $11.5 \pm 0.3$ years; height $145 \pm 7.0 \mathrm{~cm}$; body mass $37.2 \pm 4.1 \mathrm{~kg}$ ). The players were members of teams from two clubs in the Prague district of the Czechia that participated in the highest Czech youth league level. These two clubs were randomly selected from a basic sample (a total of fourteen clubs in the Prague district) and then were asked to participate in the study. The weekly cycle consisted of four training sessions $(7-8 \mathrm{~h})$ focused primarily on technical-tactical skills during exercises and games and one competitive match. The inclusion criteria were a minimum of 6.4 years of experience with organized soccer and full attendance in ongoing habitual training cycles. Exclusion criteria were any medical problems that compromised participation or performance in the study, such as soft tissue injury, delayed muscle soreness, recent illness or recent recovery from injury. The research was approved by the Ethics Committee of the Faculty of Physical Education and Sport, Charles University, and all participants and their parents signed an informed consent form.

\section{Fundamental Motor Skills}

The Bruininks-Oseretsky Test - 2nd edition (BOT-2; short version) was used to assess fundamental fine and gross motor skills (Bruininks, 2005). The BOT-2 has demonstrated high interrater reliability $(r \geq 0.90)$, test-retest reliability $(r \geq 0.80)$ and construct validity (Deitz et al., 2007). The short version contains sixteen items divided into eight dimensions (see Table 1). Raw scores from BOT-2 were transformed into standard scores according to age by ASSIST software (MN, United States). Standard scores were then used for the final analysis.
TABLE 1 | List of dimensions and items of the BOT-2 motor test.

\begin{tabular}{|c|c|}
\hline Fine motor precision & Balance \\
\hline Drawing lines through crooked paths & Walking forward on a line \\
\hline Folding paper & $\begin{array}{l}\text { Standing on one leg on a balance } \\
\text { beam - eyes open }\end{array}$ \\
\hline Fine motor integration & Running speed and agility \\
\hline Copying a square & One-legged stationary hop \\
\hline Copying a circle & Upper limb coordination \\
\hline Copying a star & $\begin{array}{l}\text { Dropping and catching a ball - both } \\
\text { hands }\end{array}$ \\
\hline Copying a pencil & Dribbling a ball - alternating hands \\
\hline Manual dexterity & Strength \\
\hline Transferring a penny & Full push-ups \\
\hline Bilateral coordination & Sit-ups - $30 s$ \\
\hline \multicolumn{2}{|l|}{$\begin{array}{l}\text { Jumping in place - same side } \\
\text { synchronized }\end{array}$} \\
\hline $\begin{array}{l}\text { Tapping feet and fingers - same side } \\
\text { synchronized }\end{array}$ & \\
\hline
\end{tabular}

\section{Physical Fitness Tests}

Three physical fitness parameters were measured (shuttle run $4 \mathrm{~m} \times 10 \mathrm{~m}$, standing broad jump, and $20-\mathrm{m}$ progressive shuttle run). These three tests are included in the Unifittest 6-60 test battery, which is standardized for the Czech context (Mekota and Kovar, 1995; Chytrackova, 2002) with a satisfactory level of reliability and validity (Mekota and Kovar, 1995). Shuttle run $4 \mathrm{~m} \times 10 \mathrm{~m}$, which assesses coordination and speed, was performed twice by each player, with 3-4 min of rest between the two trials. In a start position, the player stood on the starting line without moving into the space between photocells. The player sprinted to the opposite marker $(10 \mathrm{~m})$, turned and returned to the starting line directly adjacent to the photocell gate. This was performed twice to cover a 40-m distance. The time of the faster trial was recorded. An infrared timing gate (Alge Timing $\mathrm{GmbH}$, Lustenau, Austria) placed at approximately hip height was used for the start and finish points. Standing broad jump, an indicator of explosive power in the lower limbs, was performed three times by each player, with 2 min of rest between trials. The player stood behind a line marked on the ground. A two-foot takeoff and landing area was used, and players were instructed to jump as far as possible while swinging their arms and bending their knees to provide forward momentum. The longest jump was recorded and used for the analysis. Progressive shuttle run $20 \mathrm{~m}$ is a measure of maximal aerobic fitness. The player continuously ran between two lines $20 \mathrm{~m}$ apart, keeping pace with recorded beeps, which accelerated each minute. The test was stopped when the player failed to reach the line (within two meters) after two consecutive warnings. Finally, from each test item, a standard score was obtained. The composite score of all tests on a scale from 0 to 20 was calculated as a marker of physical fitness.

\section{Predicted Maturity Offset}

Maturity offset was estimated according to Mirwald et al. (2002) equations. Although these equations have been widely used in the sport environment (e.g., Wickel and Eisenmann, 2007; 
Gastin et al., 2013; Gil et al., 2014; Meyers et al., 2015), studies have pointed to the limits of this predictive method in both sexes (Malina and Kozieł, 2014a,b; Malina et al., 2016). In the current study, we considered the finding of Kozieł and Malina (2018), who stated that maturity offset predicted from the Mirwald equations matched the observed peak high velocity (PHV) in 12-year-old boys, to be important.

Y-PHV $=-9.326+$ (length of lower limbs $*$ sitting height $)-(0.001663 *$ [decimal age $*$ length of lower limbs] $)$ $+(0.007216 *$ [decimal age $*$ sitting height] $)+0.02292 *$ [weight/height]

Body weight was assessed with an accuracy of $0.1 \mathrm{~kg}$ using medical calibrated weight (CAS DBI-C, Lesak and Zemánek s.r.o., Czechia). A portable anthropometer (A 226, Trystom, spol. s.r.o., Czechia) with a balancing point to determine the right vertical position of the anthropometer was used for the measurement of height and sitting height $(0.1 \mathrm{~cm})$.

\section{Speed Dribbling Test}

The short dribbling test (SDT) (Bangsbo and Mohr, 2013; Figure 1) is a test of dribbling the ball at a high speed with changes in direction around a defined track. Players are required to dribble as fast as possible around the cones without touching them. The test is finished by stopping the ball in a square (defined with blue cones) at the end of the track. Each player underwent one training and one competitive trial. If the player touched any cone during dribbling, the trial failed, and the player was allowed an additional trial. Time was measured by a telemetric photocell system (Alge Timing GmbH, Lustenau, Austria), and the best time was recorded. Similar agility dribbling tests have shown acceptable reliability, with an intraclass correlation coefficient between 0.78 and 0.89 and coefficient of variation of 2.4 and 3.9 (Russell et al., 2010; Ali, 2011; Dardouri et al., 2014).

\section{Data Analysis}

Multiple regression path analysis (MRPA) was used to test the hypothesized links, with successive multiple regression equations calculated to estimate path coefficients. Mardia's, Henze-Zirkler's and Royston's multivariate normality tests were performed using

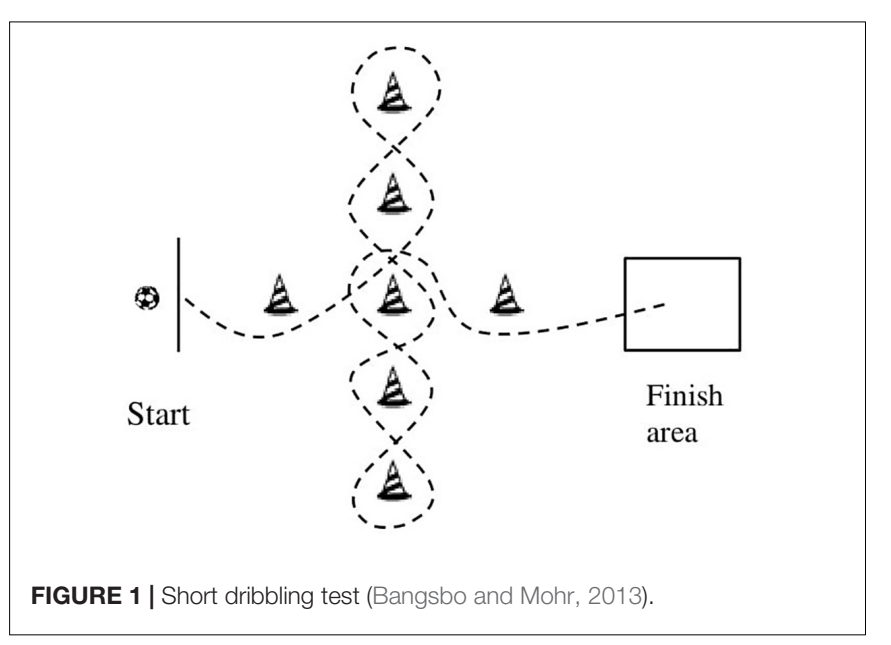

the R package MVN, version 4.0.2, in $\mathrm{R}$ 3.4.1, with a cut-off of $\mathrm{p}$ greater than 0.05 for accepting the normality of multivariate data. The exogenous independent variables were physical fitness and maturity offset. The interacting endogenous variable was FMS. All of these variables were analyzed first using linear regressions and then using multiple regressions. Subsequently, the final path analysis model was selected. In the path model, there were specified direct paths from the exogenous variable to the endogenous variable and from the exogenous and endogenous variables to the SDT. Finally, for variables that had statistically significant predictive power $(p<0.05)$ for FMS or for SDT performance, specific indirect effects via FMS were investigated. MRPA and Pearson's correlations were performed using M-plus software version 6.0 (Muthen and Muthen, 2010). All data can be found in the "Supplementary Table S1" Supplementary File.

\section{RESULTS}

The means and standard deviations of the basic descriptive statistics and correlation coefficients of FMS, physical fitness, maturity offset and speed dribbling are shown in Tables 2, 3, respectively. Significant moderate associations were observed between speed dribbling and FMS, speed dribbling and physical fitness, and FMS and physical fitness. However, there was no association between speed dribbling and maturity offset.

In the first step, we analyzed the predictive power of FMS, physical fitness and maturity offset (independent variables) on speed dribbling performance (dependent variable). The linear regression results (Table 4) showed that FMS and physical fitness are significant predictors of speed dribbling performance. Nevertheless, only the effect of FMS $\left(R^{2}=0.36 ; t=2.97\right.$; $p=0.003)$ was significant, while the effect of physical fitness was $\operatorname{not}\left(R^{2}=0.18 ; t=1.64 ; p=0.100\right)$.

Since clear evidence of the relationship between biological age and physical fitness in pubescent soccer players has been reported in previous research (biologically advanced players achieve better performance in physical fitness), we verified whether FMS and maturity offset are significant predictors of the level of physical fitness. The multiple regression model showed that the effects of FMS and maturity offset explain $22 \%$ of physical fitness performance variability $\left(R^{2}=0.22\right)$. Furthermore, from Table 5, it is clear that FMS are significantly better predictors for physical fitness than maturity offset in prepubescent players.

Considering these findings, we decided to use the analysis model where FMS plays the role of mediator between physical fitness (as the independent variable) and speed dribbling (as the dependent variable representing specific soccer skills). In the 1st path analysis model, we specified both direct and indirect paths between physical fitness and speed dribbling. The 1st path analysis model (Figure 2) showed that the direct effect of physical fitness on speed dribbling was non-significant (standard estimation $=-0.17, p=0.247$ ), and the indirect effect through FMS was significant (standard estimation $=-0.26, p=0.005$ ). To obtain better results, we decided to formulate the 2 nd path analysis model without a direct effect (Figure 3). The 2nd model was approved as significant and acceptable with empirical data 
TABLE 2 | Basic descriptive statistics $(n=40)$.

\begin{tabular}{|c|c|c|c|c|c|}
\hline & Mean & SD & Median & $\begin{array}{l}\text { Interquartile } \\
\text { range }\end{array}$ & $\begin{array}{c}95 \% \text { confidence } \\
\text { interval }\end{array}$ \\
\hline Age (years) & 11.50 & 0.30 & 11.63 & 0.42 & \pm 0.09 \\
\hline Height (cm) & 145.00 & 7.00 & 149.45 & 6.53 & \pm 1.98 \\
\hline Body mass (kg) & 37.20 & 4.10 & 37.15 & 7.85 & \pm 2.05 \\
\hline Index BMI (kg/m²) & 17.52 & 1.89 & 17.06 & 2.08 & \pm 0.59 \\
\hline FMS (ss) & 57.33 & 8.88 & 58.50 & 17.25 & \pm 2.75 \\
\hline Physical fitness (ss) & 21.05 & 3.34 & 21.00 & 4.50 & \pm 1.03 \\
\hline Maturity offset (years) & -2.88 & 0.30 & -2.90 & 0.34 & \pm 0.09 \\
\hline Speed dribbling (s) & 13.68 & 1.53 & 13.73 & 2.46 & \pm 0.47 \\
\hline
\end{tabular}

FMS, fundamental motor skills; SD, standard deviation; ss, standard score.

TABLE 3 | Correlation matrix of the study variables.

\begin{tabular}{lccc}
\hline & $\begin{array}{c}\text { Maturity } \\
\text { offset }\end{array}$ & $\begin{array}{c}\text { Physical } \\
\text { fitness }\end{array}$ & FMS \\
\hline Maturity offset & 1 & & \\
Physical fitness & $-0.21^{* *}$ & 1 & 1 \\
FMS & $-0.29^{* *}$ & $0.50^{* *}$ & $-0.60^{* *}$ \\
Speed dribbling & -0.03 & $-0.42^{* *}$ &
\end{tabular}

FMS, fundamental motor skills; **indicates statistical significance of $p<0.01$.

TABLE 4 | Linear regressions of physical fitness, FMS and maturity offset on speed dribbling.

\begin{tabular}{lccccc}
\hline Independent variable & $\boldsymbol{B}$ & $\boldsymbol{S E} \boldsymbol{B}$ & $\boldsymbol{\beta}$ & $\boldsymbol{t}$ & $\boldsymbol{p}$-Value \\
\hline Physical fitness & -0.93 & 0.31 & -0.43 & 3.28 & $0.001^{* *}$ \\
FMS & -3.5 & 0.74 & -0.60 & 5.95 & $<0.001^{* *}$ \\
Maturity offset & -0.01 & 0.03 & -0.03 & 0.19 & 0.85
\end{tabular}

FMS, fundamental motor skills; **indicates statistical significance of $p<0.01 ; B$, unstandardized beta; SE B, standard error for the unstandardized beta; $\beta$, the standardized beta; $t$, $t$-test statistic.

TABLE 5 | Multiple regression of FMS and maturity offset on physical fitness.

\begin{tabular}{lrrrrc}
\hline Independent variable & $\boldsymbol{B}$ & $\boldsymbol{S E} \boldsymbol{B}$ & $\boldsymbol{\beta}$ & $\boldsymbol{t}$ & $\boldsymbol{p}$-Value \\
\hline FMS & -0.82 & 0.06 & 0.48 & 3.25 & $0.003^{* *}$ \\
Maturity offset & 0.18 & 1.64 & 0.08 & 0.50 & 0.62 \\
Adjusted $\boldsymbol{R}^{2}$ & 0.22 & & & &
\end{tabular}

FMS, fundamental motor skills; **indicates statistical significance of $p<0.01 ; B$, unstandardized beta; SE B, standard error for the unstandardized beta; $\beta$, the standardized beta; $t$, $t$-test statistic.

explaining more than $25 \%$ of the model. Generally, FMS were a significant mediator between physical fitness and speed dribbling (standard estimation $=-0.31, p=0.001$ ).

\section{DISCUSSION}

The present study examined the possible role of FMS in the relationships between physical fitness and biological maturation and speed dribbling as a soccer-specific soccer skill in young soccer players. We found that FMS were a significant mediator of the relationship between physical fitness and speed dribbling.
Notably, biological maturation did not prove to be a significant contributor to speed dribbling performance through FMS. Despite moderate correlations between physical fitness and speed dribbling, the path model did not reveal a direct influence of physical fitness or biological maturation on speed dribbling. These findings suggest the need for a certain level of FMS (fine and gross motor skills) to acquire soccer-specific motor skills. Generally, both quantitative (physical fitness) and qualitative (FMS) motor aspects were found to be significant contributors to the performance of soccer-specific motor skills, represented by speed dribbling. Our path model revealed that FMS, physical fitness and other related factors have a prior effect on specific skill, whereas biological maturation might explain only $8.7 \%$ of motor coordination (Freitas et al., 2016).

Our results suggest that FMS mastery significantly increases the influence of physical fitness on the performance of soccer-specific skills in young players. These findings are in accordance with Clark and Metcalfs (2002) statement that FMS are basic elements for later skillfulness in a range of sport and game domains. Our results cannot be compared with similar data measured on soccer players. However, similar conclusions have been found in research involving combat sports (Bozanic and Beslija, 2010), where high correlations were found between specific karate skills and FMS $(r=0.74)$ in 5 - to 7 -year-old members of karate clubs. This study suggested that children with higher FMS also have better karate techniques, while others have difficulties acquiring these techniques. Unfortunately, recent research has documented very poor or insufficient FMS performance in preschool and school-aged children (Okely et al., 2004; Erwin and Castelli, 2008; Hardy et al., 2010; Kokstejn et al., 2017a,b) combined with generally unresolved inactivity in children (Faigenbaum et al., 2018), which may result in impaired acquisition of more complex and difficult sport skills or delays in mastering the required skills. Similarly, the players in our study showed only an average level of FMS even though they were considered to be capable of high performance. Since a higher level of FMS and soccer-specific skills were found in players selected for Belgian professional clubs (Deprez D.N. et al., 2015) than in "dropout" players, FMS and soccer-specific skills seem to be crucial to the identification of gifted players and their likelihood of remaining in high-level talent development programs.

Our participants were at a specific age (U12) where physical development plateaus (in reactive strength and jumping) with a 


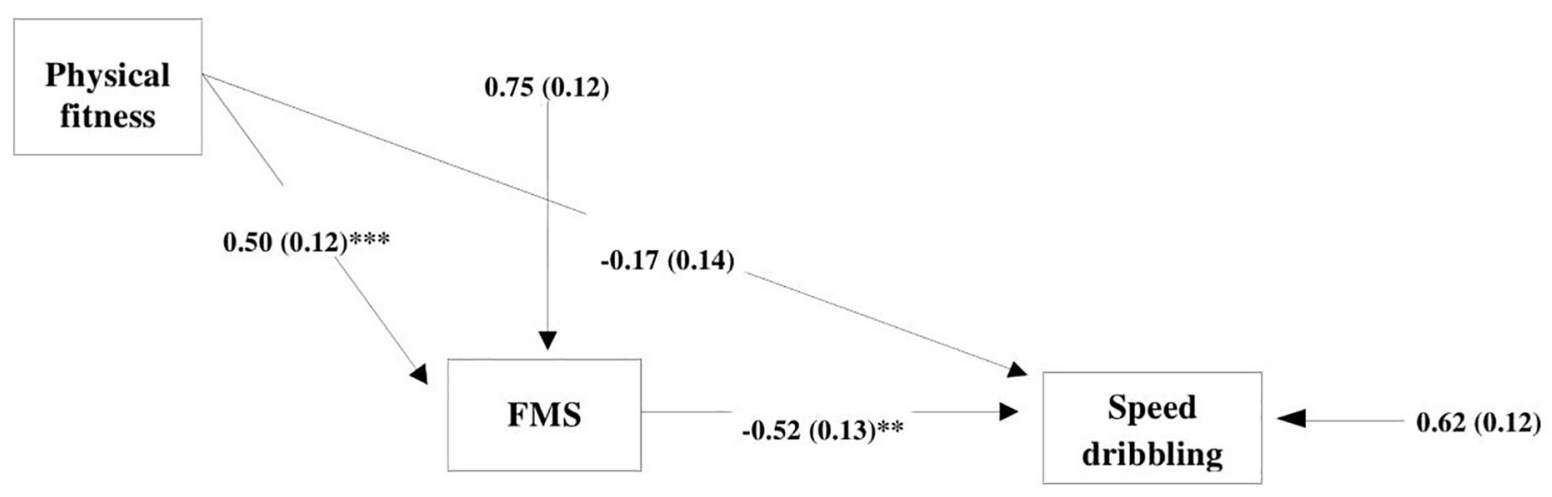

FIGURE 2 | First path analysis model with direct and indirect effects of physical fitness and FMS on speed dribbling [Satorra-Bentler $\chi^{2}(d f=0)=0 ; p=0.00$; RMSEA = 0.0; SRMR =0.0; CFI = 0.0; TLI = 0.0]; FMS, fundamental motor skills. ${ }^{* *} p<0.01 ;{ }^{* * *} p<0.001$.

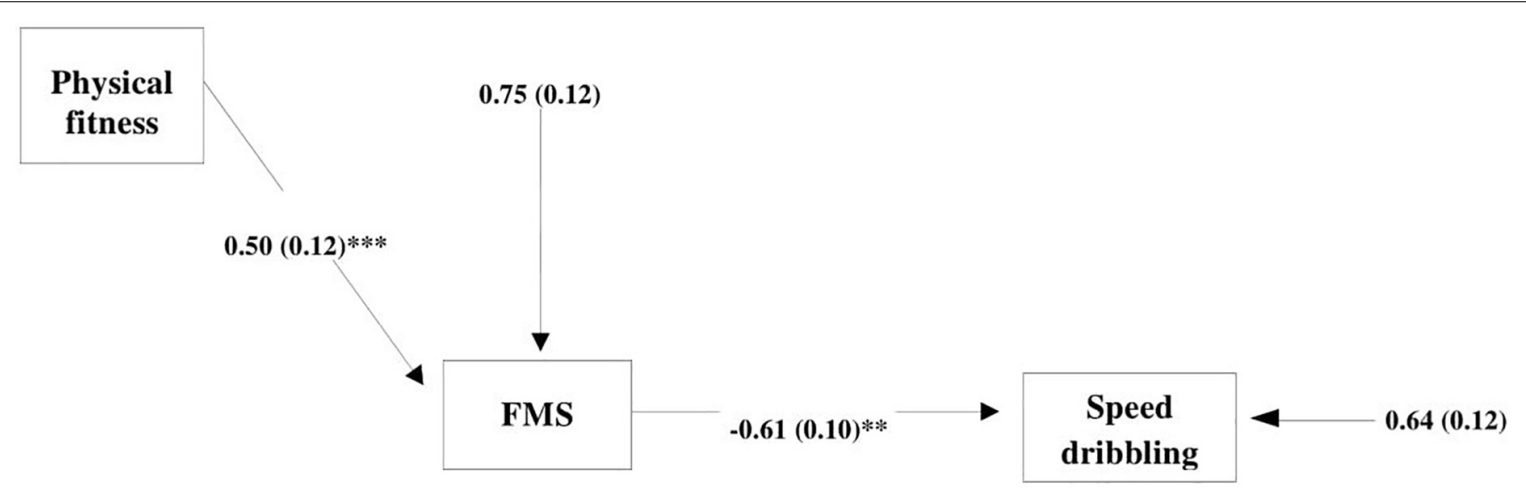

FIGURE 3 | Second path analysis model with only the indirect effect of physical fitness on speed dribbling with FMS as the mediator variable [Satorra-Bentler $\chi^{2}$ $(d f=1)=1.3 ; p=0.254 ;$ RMSEA $=0.08 ;$ SRMR $=0.04 ; \mathrm{CFI}=0.99 ; \mathrm{TLI}=0.97]$; FMS, fundamental motor skills. ${ }^{* *} p<0.01 ; * * * p<0.001$.

change in the mechanical properties of the lower limb (decreased relative leg stiffness), which has been previously observed (Lloyd et al., 2011). This might explain why biological maturation in U12 children is not strongly related to physical fitness or motor control testing (Freitas et al., 2016) and why separate values of physical fitness and biological maturation are insufficient for predicting a player's ability to acquire soccer-specific skills. Our path models suggest that the best performance of soccer-specific skills will occur in players with adequate levels of both FMS and physical fitness. This finding is in agreement with the finding that FMS were a long-term predictor of explosive power in soccer players from childhood to young adulthood (Deprez D. et al., 2015). Therefore, we believe that well-developed FMS and the simultaneous development of PF are necessary in pre-PHV boys and that well-coordinated players will improve in power and performance with age due to increased tendon stiffness in late adolescence (Deprez D. et al., 2015).

The harmony between physical fitness and biological maturation has been highlighted by several authors (e.g., Meylan et al., 2010; Unnithan et al., 2012; Vandendriessche et al., 2012) to discriminate elite, subelite and non-elite soccer players during talent identification. Moreover, FMS were found to be a long-term predictor of soccer-specific aerobic performance in elite pubertal soccer players (Deprez et al., 2014) and children (Hands, 2008). Specifically, children with low FMS performed worse on all fitness tests (50-m run, standing broad jump and endurance shuttle run), where endurance shuttle test differences increased between low- and high-FMS groups over 5 years (Hands, 2008). Therefore, we highlight the importance of FMS not only for soccer-specific motor skills but also for separate components of physical fitness, such as explosive power and aerobic endurance, during long-term motor development.

Several possible limitations associated with this study should be noted. The present study utilized a cross-sectional design; thus, the role of FMS in the relationships between physical fitness, biological maturation and soccer-specific motor skills should be interpreted with caution. A longitudinal follow-up of young soccer players, especially during the pubertal phase (aged 12-15 years), may provide a more accurate explanation of this mediation effect. Another possible limitation is related to the non-inclusion of psychological variables such as motivation or self-confidence, which certainly influence game performance and likely also affect the development of new soccer-specific motor skills. Lastly, although several authors consider speed dribbling the most valid soccer skill test, the inclusion of additional soccer-specific skills (e.g., passing, shooting, receiving, 
or multifaceted tests) could elucidate the role of FMS in the acquisition of soccer-specific motor skills (Vanderford et al., 2004). Therefore, future research should focus on (1) performing longitudinal research to verify the role of FMS in acquiring soccer-specific skills during the pubertal phase, (2) testing more soccer-specific skills and psychological variables with respect to players' positions, and (3) using a process-oriented (assessment of movement quality) test for FMS assessment.

\section{CONCLUSION}

This is the first study to evaluate the role of FMS in a complex theoretical model with the relationships between physical fitness, biological maturation and soccer-specific motor skill (measured using speed dribbling) in young soccer players. Our results showed that FMS significantly strengthened the influence of physical fitness on the performance of speed dribbling, a soccer-specific motor skill, and thus play an important role in the process of the acquisition of sport-specific motor skills in prepubertal elite soccer players. Conversely, physical fitness and biological maturation alone did not significantly influence speed dribbling performance. Generally, it appears that developing and improving a wide range of basic FMS as building blocks for more complex and more difficult soccer-specific motor skills is necessary during the long-term training process. Based on these findings, FMS could be included in TID programs for young elite soccer players, especially during childhood and before puberty. Thus, it is recommended that youth soccer coaches and practitioners carefully consider providing training on FMS (fine motor, locomotor, object control, balance), especially during childhood, with an emphasis on the quality of movements.

\section{DATA AVAILABILITY}

All datasets generated for this study are included in the manuscript and/or the Supplementary Files.

\section{REFERENCES}

Ali, A. (2011). Measuring soccer skill performance: a review. Scand. J. Med. Sci. Sports 21, 170-183. doi: 10.1111/j.1600-0838.2010.01256.x

Aquino, R., Puggina, E. F., Alves, I. S., and Garganta, J. (2017). Skill-related performance in soccer: a systematic review. Hum. Mov. 18, 3-24.

Bangsbo, J., and Mohr, M. (2013). Fitness Testing in Football. Espergærde: Bangsbosport.

Bozanic, A., and Beslija, T. (2010). Relations between fundamental motor skills and specific karate technique in 5-7 year old begginers. Sport Sci. 3, 79-83.

Bruininks, R. H. (2005). Bruininks-Oseretsky Test of Motor Proficiency. Circle Pines, MN: AGS Publishing.

Chytrackova, J. (2002). Př́ručka pro Manuální a Počitačové Hodnocení Základní Motorické Výkonnosti a Vybraných Charakteristik Tilesné Stavby Mládeže a Dospilých v Ėeské Republice [Manual for Manual and Computer Assessment of Motor Performance and Selected Parameters of Body Composition in Youth and Adult in Czech Republic], 1st Edn. Prague: Charles University FTVS.

\section{ETHICS STATEMENT}

This study was carried out in accordance with the recommendations of "name of guidelines, name of committee" with written informed consent from all subjects. All subjects gave written informed consent in accordance with the Declaration of Helsinki. The protocol was approved by the "name of committee."

\section{AUTHOR CONTRIBUTIONS}

JK, MM, and PS involved in the conceptualization of the study design and the drafting of the manuscript. JK and MM involved in data collection. JK involved in performing an overview of the previous research. MM involved in conducting the statistical analysis. PW and EM-C helped with the data assessment and interpretation.

\section{FUNDING}

This study was supported by the project UNCE No. 032, GA19-12150S and the Progress Q19 Social-Sciences Aspects of Human Movement Studies II program.

\section{ACKNOWLEDGMENTS}

The authors would like to thank the participating players and their coaches (particularly Mr. Ales Vytlacil and Mr. Oldrich Smerda) from AC Sparta Prague for their effort and support during the research activities connected with this study.

\section{SUPPLEMENTARY MATERIAL}

The Supplementary Material for this article can be found online at: https://www.frontiersin.org/articles/10.3389/fphys. 2019.00596/full\#supplementary-material

Clark, J. E., and Metcalf, J. S. (2002). "The mountain of motor development: a metaphor," in Motor Development: Reserch and Reviews, eds J. E. Clark and J. H. Humphrey (Reston, VA: National Associotion for Sport and Physical Education), 163-190.

Costa, I. T. D., Garganta, J., Greco, P. J., Mesquita, I., and Seabra, A. (2010). Influence of relative age effects and quality of tactical behaviour in the performance of youth soccer players. Int. J. Perform. Anal. Sport 10, 82-97.

Cumming, S. P., Brown, D. J., Mitchell, S., Bunce, J., Hunt, D., Hedges, C., et al. (2018). Premier League academy soccer players' experiences of competing in a tournament bio-banded for biological maturation. J. Sports Sci. 36, 757-765. doi: 10.1080/02640414.2017.1340656

Dardouri, W., Selmi, M. A., Sassi, R. H., Gharbi, Z., Rebhi, A., and Moalla, W. (2014). Reliability and discriminative power of soccer-specific field tests and skill index in young soccer players. Sci. Sports 29, 88-94.

Deitz, J. C., Kartin, D., and Kopp, K. (2007). Review of the BruininksOseretsky test of motor proficiency, (BOT-2). Phys. Occup. Ther. Pediatr. 27, 87-102. 
Deprez, D., Valente-dos-Santos, J., Coelho-e-Silva, M., Lenoir, M., Philippaerts, R. M., and Vaeyens, R. (2014). Modeling developmental changes in the yo-yo intermittent recovery test level 1 in elite pubertal soccer players. Int. J. Sports Physiol. Perform. 9, 1006-1012. doi: 10.1123/ijspp.2013-0368

Deprez, D., Valente-Dos-Santos, J., Coelho-e-Silva, M. J., Lenoir, M., Philippaerts, R., and Vaeyens, R. (2015). Longitudinal development of explosive leg power from childhood to adulthood in soccer players. Int. J. Sports Med. 36, 672-679. doi: 10.1055/s-0034-1398577

Deprez, D. N., Fransen, J., Lenoir, M., Philippaerts, R. M., and Vaeyens, R. (2015). A retrospective study on anthropometrical, physical fitness, and motor coordination characteristics that influence dropout, contract status, and first-team playing time in high-level soccer players aged eight to eighteen years. J. Strength Cond. Res. 29, 1692-1704. doi: 10.1519/JSC.000000000000 0806

Deutscher Fuûball Bund (2009). TalentfoÈrderprogramm. Leitfaden fuÈ $r$ die Ausbildung [Talent Development Programme. Training guidline]. Philippka: MuẼnster.

Erwin, H. E., and Castelli, D. M. (2008). National physical education standards: a summary of student performance and its correlates. Res. Q. Exerc. Sport 79, 495-505.

Faigenbaum, A. D., Rial Rebullido, T., and MacDonald, J. P. (2018). The unsolved problem of paediatric physical inactivity: it's time for a new perspective. Acta Paediatr. 107, 1857-1859.

Figueiredo, A. J., Gonçalves, C. E., Coelho-e-Silva, M. J., and Malina, R. M. (2009). Youth soccer players, 11-14 years: maturity, size, function, skill and goal orientation. Ann. Hum. Biol. 36, 60-73. doi: 10.1080/0301446080257 0584

Forsman, H., Gråstén, A., Blomqvist, M., Davids, K., Liukkonen, J., and Konttinen, N. (2016). Development of perceived competence, tactical skills, motivation, technical skills, and speed and agility in young soccer players. J. Sports Sci. 34, 1311-1318. doi: 10.1080/02640414.2015.1127401

Freitas, D. L., Lausen, B., Maia, J. A., Gouveia, E. R., Thomis, M., Lefevre, J., et al. (2016). Skeletal maturation, body Size, and motor coordination in youth 11-14 years. Med. Sci. Sports Exerc. 48, 1129-1135. doi: 10.1249/MSS. 0000000000000873

Gallahue, D. L., Ozmun, J. C., and Goodway, J. (2012). Understanding Motor Development: Infants, Children, Adolescents, Adults. New York, NY: McGrawHill.

Gastin, P. B., Bennett, G., and Cook, J. (2013). Biological maturity influences running performance in junior Australian football. J. Sci. Med. Sport 16, 140-145. doi: 10.1016/j.jsams.2012.05.005

Gil, S. M., Badiola, A., Bidaurrazaga-Letona, I., Zabala-Lili, J., Gravina, L., SantosConcejero, J., et al. (2014). Relationship between the relative age effect and anthropometry, maturity and performance in young soccer players. J. Sports Sci. 32, 479-486. doi: 10.1080/02640414.2013.832355

Hands, B. (2008). Changes in motor skill and fitness measures among children with high and low motor competence: a five-year longitudinal study. J. Sci. Med. Sport 11, 155-162.

Hardy, L. L., King, L., Farrell, L., Macniven, R., and Howlett, S. (2010). Fundamental movement skills among Australian preschool children. J. Sci. Med. Sport 13, 503-508. doi: 10.1016/j.jsams.2009.05.010

Höner, O., Leyhr, D., and Kelava, A. (2017). The influence of speed abilities and technical skills in early adolescence on adult success in soccer: a longterm prospective analysis using ANOVA and SEM approaches. PLoS One 12:e0182211. doi: 10.1371/journal.pone.0182211

Huijgen, B. C., Elferink-Gemser, M. T., Ali, A., and Visscher, C. (2013). Soccer skill development in talented players. Int. J. Sports Med. 34, 720-726. doi: 10.1055/s-0032-1323781

Huijgen, B. C., Elferink-Gemser, M. T., Lemmink, K. A., and Visscher, C. (2014). Multidimensional performance characteristics in selected and deselected talented soccer players. Eur. J. Sport Sci. 14, 2-10. doi: 10.1080/17461391.2012. 725102

Huijgen, B. C., Elferink-Gemser, M. T., Post, W. J., and Visscher, C. (2009). Soccer skill development in professionals. Int. J. Sports Med. 30, 585-591. doi: 10.1055/ s-0029-1202354

Kokstejn, J., Musalek, M., Stastny, P., and Golas, A. (2017a). Fundamental motor skills of Czech children at the end of the preschool period. Acta Gymn. 47, 193-200.
Kokstejn, J., Musalek, M., and Tufano, J. J. (2017b). Are sex differences in fundamental motor skills uniform throughout the entire preschool period? PLoS One 12:e0176556. doi: 10.1371/journal.pone.0176556

Kozieł, S. M., and Malina, R. M. (2018). Modified maturity offset prediction equations: validation in independent longitudinal samples of boys and girls. Sports Med. 48, 221-236. doi: 10.1007/s40279-017-0750-y

Leyhr, D., Kelava, A., Raabe, J., and Höner, O. (2018). Longitudinal motor performance development in early adolescence and its relationship to adult success: an 8-year prospective study of highly talented soccer players. PLoS One 13:e0196324. doi: 10.1371/journal.pone.0196324

Lloyd, R. S., Oliver, J. L., Hughes, M. G., and Williams, C. A. (2011). The influence of chronological age on periods of accelerated adaptation of stretch-shortening cycle performance in pre and postpubescent boys. J. Strength Cond. Res. 25, 1889-1897. doi: 10.1519/JSC.0b013e3181e7faa8

Malina, R. M., Choh, A. C., Czerwinski, S. A., and Chumlea, W. C. (2016). Validation of maturity offset in the Fels longitudinal study. Pediatr. Exerc. Sci. 28, 439-455. doi: 10.1123/pes.2015-0090

Malina, R. M., and Kozieł, S. M. (2014a). Validation of maturity offset in a longitudinal sample of Polish boys. J. Sports Sci. 32, 424-437. doi: 10.1080/ 02640414.2013.828850

Malina, R. M., and Kozieł, S. M. (2014b). Validation of maturity offset in a longitudinal sample of Polish girls. J. Sports Sci. 32, 1374-1382. doi: 10.1080/ 02640414.2014 .889846

Mekota, K., and Kovar, R. (1995). Unifittest (6-60): Test and Norms of Motor Performance and Physical Fitness in Youth and in Adult Age. Olomouc: Palacký University.

Meyers, R. W., Oliver, J. L., Hughes, M. G., Cronin, J. B., and Lloyd, R. S. (2015). Maximal sprint speed in boys of increasing maturity. Pediatr. Exerc. Sci. 27, 85-94. doi: 10.1123/pes.2013-0096

Meylan, C., Cronin, J., Oliver, J., and Hughes, M. (2010). Talent identification in soccer: the role of maturity status on physical, physiological and technical characteristics. Int. J. Sports Sci. Coach. 5, 571-592.

Mirwald, R. L., Baxter-Jones, A. D., Bailey, D. A., and Beunen, G. P. (2002). An assessment of maturity from anthropometric measurements. Med. Sci. Sports Exerc. 34, 689-694.

Murtagh, C. F., Brownlee, T. E., O’Boyle, A., Morgans, R., Drust, B., and Erskine, R. M. (2018). Importance of speed and power in elite youth soccer depends on maturation status. J. Strength Cond. Res. 32, 297-303. doi: 10.1519/JSC. 0000000000002367

Muthen, L. K., and Muthen, B. O. (2010). Mplus: Statistical Analysis with Latent Variables: User's Guide. Los Angeles, CA: Muthén \& Muthén.

Okely, A. D., Booth, M. L., and Chey, T. (2004). Relationships between body composition and fundamental movement skills among children and adolescents. Res. Q. Exerc. Sport 75, 238-247.

O'Brien, W., Belton, S., and Issartel, J. (2016). Fundamental movement skill proficiency amongst adolescent youth. Phys. Educ. Sport Pedagog. 21, 557-571. doi: 10.1080/02640414.2015.1096017

Philippaerts, R. M., Vaeyens, R., Janssens, M., Van Renterghem, B., Matthys, D., Craen, R., et al. (2006). The relationship between peak height velocity and physical performance in youth soccer players. J. Sports Sci. 24, 221-230.

Rampinini, E., Impellizzeri, F. M., Castagna, C., Coutts, A. J., and Wisløff, U. (2009). Technical performance during soccer matches of the Italian serie a league: effect of fatigue and competitive level. J. Sci. Med. Sport 12, 227-233.

Reilly, T., Williams, A. M., Nevill, A., and Franks, A. (2000). A multidisciplinary approach to talent identification in soccer. J. Sports Sci. 18, 695-702.

Robinson, L. E., Stodden, D. F., Barnett, L. M., Lopes, V. P., Logan, S. W., Rodrigues, L. P., et al. (2015). Motor competence and its effect on positive developmental trajectories of health. Sports Med. 45, 1273-1284. doi: 10.1007/ s40279-015-0351-6

Rommers, N., Mostaert, M., Goossens, L., Vaeyens, R., Witvrouw, E., Lenoir, M., et al. (2018). Age and maturity related differences in motor coordination among male elite youth soccer players. J. Sports Sci. 37, 196-203. doi: 10.1080/ 02640414.2018.1488454

Russell, M., Benton, D., and Kingsley, M. (2010). Reliability and construct validity of soccer skills tests that measure passing, shooting, and dribbling. J. Sports Sci. 28, 1399-1408. doi: 10.1080/02640414.2010.511247 
Serrano, J. S., Pizarro, A. P., García-González, L., Domínguez, A. M., and Álvarez, F. V. (2017). Evolution of tactical behavior of soccer players across their development. Int. J. Perform. Anal. Sport 17, 885-901.

Unnithan, V., White, J., Georgiou, A., Iga, J., and Drust, B. (2012). Talent identification in youth soccer. J. Sports Sci. 30, 1719-1726. doi: 10.1080/ 02640414.2012 .731515

Vaeyens, R., Lenoir, M., Williams, A. M., and Philippaerts, R. M. (2008). Talent identification and development programmes in sport: current models and future directions. Sports Med. 38, 703-714.

Vaeyens, R., Malina, R. M., Janssens, M., Van Renterghem, B., Bourgois, J., Vrijens, J., et al. (2006). A multidisciplinary selection model for youth soccer: the ghent youth soccer project. Br. J. Sports Med. 40, 928-934.

Valente-dos-Santos, J., Coelho-e-Silva, M. J., Simoes, F., Figueiredo, A. J., Leite, N., Elferink-Gemser, M. T., et al. (2012). Modeling developmental changes in functional capacities and soccer-specific skills in male players aged 11-17 years. Pediatr. Exerc. Sci. 24, 603-621.

Vandendriessche, J. B., Vaeyens, R., Vandorpe, B., Lenoir, M., Lefevre, J., and Philippaerts, R. M. (2012). Biological maturation, morphology, fitness, and motor coordination as part of a selection strategy in the search for international youth soccer players (age 15-16 years). J. Sports Sci. 30, 1695-1703.

Vanderford, M. L., Meyers, M. C., Skelly, W. A., Stewart, C. C., and Hamilton, K. L. (2004). Physiological and sport-specific skill response of olympic youth soccer athletes. J. Strength Cond. Res. 18, 334-342.

Wickel, E. E., and Eisenmann, J. C. (2007). Maturity-related differences in physical activity among 13-to 14-year-old adolescents. Ped. Exerc. Sci. 19, 384-392.

Conflict of Interest Statement: The authors declare that the research was conducted in the absence of any commercial or financial relationships that could be construed as a potential conflict of interest.

Copyright (c) 2019 Kokstejn, Musalek, Wolanski, Murawska-Cialowicz and Stastny. This is an open-access article distributed under the terms of the Creative Commons Attribution License (CC BY). The use, distribution or reproduction in other forums is permitted, provided the original author(s) and the copyright owner(s) are credited and that the original publication in this journal is cited, in accordance with accepted academic practice. No use, distribution or reproduction is permitted which does not comply with these terms. 